\title{
La apertura subjetiva como el fundamento de la utopía y la esperanza
}

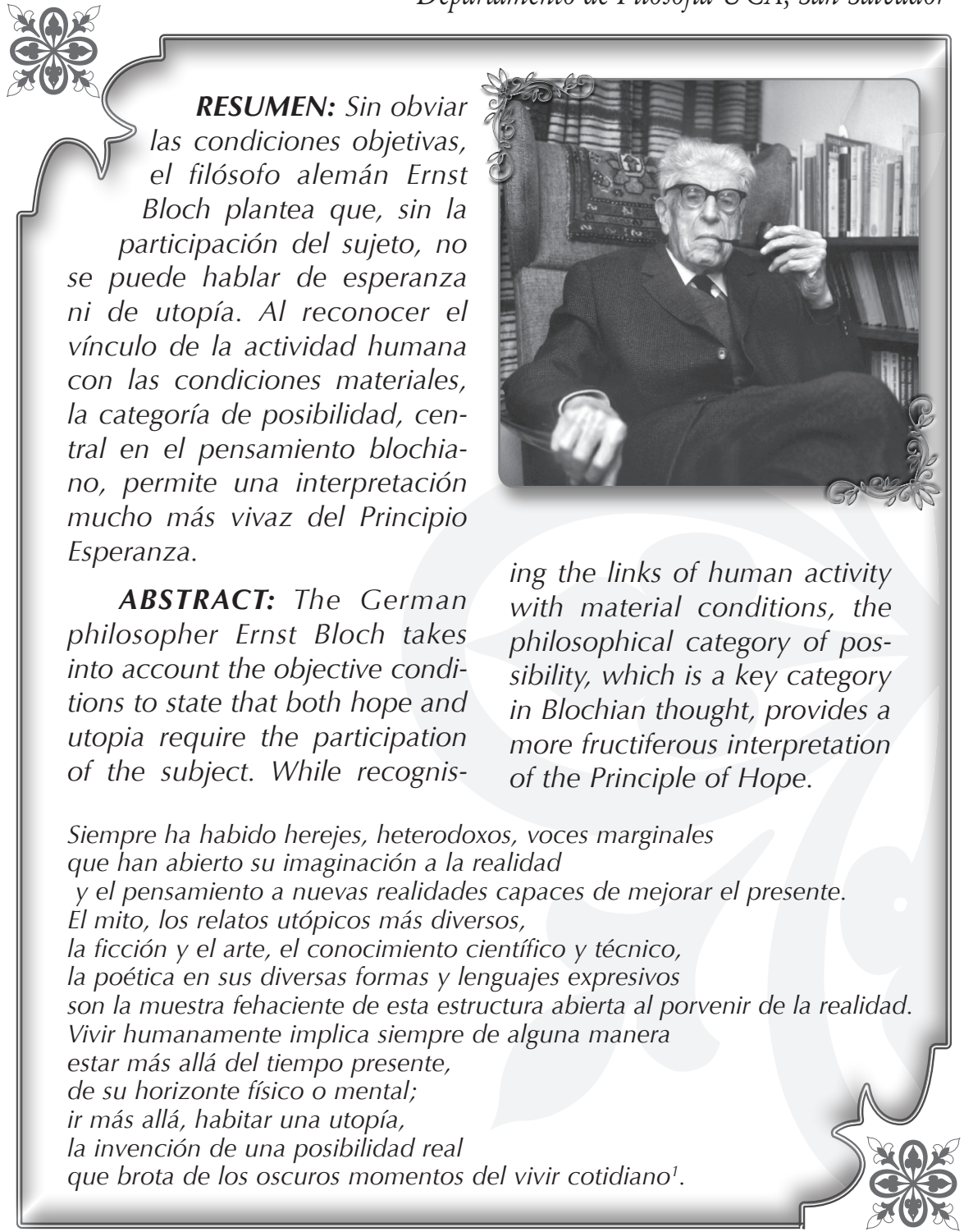

Departamento de Filosofía UCA, San Saluador 
¿ Es posible abordar temas

$\sum$ Como la esperanza y la utopía sin aludir al sujeto que las encarna? ¿Es viable hablar de cambios históricos, políticos y económicos soslayando la participación de aquél que los anticipa y dinamiza? Las respuestas contundentemente negativas de estas interrogantes constituyen la justificación y andamiaje de la antropología filosófica de Ernst Bloch. La famosa invitación del Oráculo de Delfos: "conócete a ti mismo", encuentra eco en una peculiar reflexión filosófica que sostiene la imposibilidad de dar cuenta de la realidad sin descifrar el enigma de la existencia humana. La mejor evidencia de esta postura la encontramos en el prólogo de su Principio Esperanza, donde la posición privilegiada del ámbito antropológico se hace palpable. Preguntas inquietantes como quién somos, de dónde venimos, a dónde vamos, qué esperamos, qué nos espera; representan el vector de una indagación filosófica que concibe al ser humano como el protagonista principal de las transformaciones socio-políticas. Se trata del hombre como centro de la reflexión, pues en él la esperanza encuentra las manos que pueden edificarla.
No obstante, esta primariedad subjetiva en el análisis filosófico no significa soslayar las condiciones objetivas desde las cuales el hombre se desenvuelve. Este punto es decisivo para comprender la antropología blochiana, pues reconociendo la vinculación de la actividad humana con las condiciones materiales, la categoría de posibilidad, central en el entramado filosófico blochiano, permite que la esperanza adquiera un nuevo y fortalecido matiz. La esperanza abandona su ropaje estéril; el conformismo que la mantenía atada es fustigado por Bloch. Desembarazada de las situaciones quiméricas y alienantes, el futuro se convierte en su compañero de viaje, adquiriendo la fertilidad idónea para que el hombre atisbe los proyectos transformadores del presente.

La categoría posibilidad está presente de manera constitutiva en el hombre y en el mundo. Esta categoría invade hasta el último resquicio de los correlatos subjetivo y objetivo, dotándoles de apertura. Por ende, el ser humano, considerado como el máximo apogeo de la realidad material, aguarda su plena realización en un ahora abierto y plagado de posibilidades. Bloch resume este punto:

Así, empero, hay algo abierto, y su impulso, su deseo, su acción, tiene su sitio. Lo que no es puede todavía llegar a ser, lo que se ha realizado presupone lo posible en su materia. Este algo abierto se da en el hombre, y sueños y proyectos viven aquí. Lo abierto se da igualmente en las cosas, en su borde frontero, allí donde el devenir todavía es posible². 
Y deja sentado que:

Lo verdaderamente propio no se ha realizado aún ni en el hombre ni en el mundo, se halla en espera, en el temor de perderse, en la esperanza de lograrse ${ }^{3}$.

Contra todo reduccionismo, insistirá Bloch en la relación dialéctica sujeto-objeto, donde la posibilidad genera una oscilación indeterminada. Este postulado permite desestimar interpretaciones marxistas de raigambre determinista. Por ello, desde el planteamiento de Bloch aunque resulte imposible el análisis antropológico soslayando las condiciones materiales, es igualmente inviable cualquier concepción de los procesos objetivos que sepulte las aspiraciones subjetivas. El siguiente párrafo indica su convicción:

Yo afirmo que el mundo está abierto, que una posibilidad objetivamente real existe en él y que no se halla simplemente determinado por la necesidad ni sometido a ningún determinismo mecánico. La intuición marxista degenera nuevamente en el fetiche rígido: primero, a causa de su excesiva depreciación del hombre individual, y segundo, por su noción de que el proceso del

mundo casi puede seguir adelante sin nosotros, arrastrándonos por los pelos (valga la expresión), quemarnos o no movernos ${ }^{4}$.

Sintetizando, la apertura del mundo y del ser humano tiene su punto de correspondencia en la posibilidad. Es decir, el hombre y su mundo se hallan de manera indefinida dentro del proceso dialéctico-material. La concepción de una relación sujeto-objeto prefijada e inmóvil es descartada por Bloch.

Lejos de toda consigna paralizante, nuestro autor estipula las proposiciones fundantes del desenvolvimiento humano: sujeto incosificado y objeto mostrado. El primero, entendido como el ser privilegiado de la realidad material, aquél que activa y permanece al frente de los procesos históricos. El segundo, establecido como elemento independiente a la conciencia, pero que otorga la base ineludible de toda transformación real. Bloch resume esta vinculación:

La independencia del mundo exterior respecto a la conciencia, su objetividad no sólo queda suprimida por la mediación del trabajo con el mundo exterior, sino que por razón de ella queda precisamente formulada de modo definitivo. Porque así como la misma actividad humana es una actividad objetiva, es decir, que no cae fuera del mundo exterior, así también la mediación sujeto-objeto, en tanto que tiene lugar, es así mismo un trozo del mundo exterior ${ }^{5}$. 
En Bloch nada permanece inmóvil y acabado, sino plagado de posibilidades a realizar. Por eso mismo, la realidad necesita de la praxis para consumar todas las po- tencialidades pendientes. La frase blochiana: "las cosas nos necesitan" expresa la importancia subjetiva y se torna comprensible desde la siguiente acotación:

El hombre, activo y subjetivo, debe armonizar con el movimiento objetivo de la realidad. Ha de escuchar con sentido casi musical el movimiento de la realidad y preguntar: ¿en qué dirección hay que tocar la melodía?

Las palabras de Bloch hacen referencia al tema de la primacía subjetiva. En efecto, la primariedad subjetiva se constata en el carácter conciente de su praxis y es antípoda de cualquier idealismo del ser o determinismos sustentados en procesos históricos o económicos. Para Bloch, lejos de todo derrotismo reduccionista, únicamente el sujeto que indaga en el mundo buscando el afincamiento y dirección adecuada podrá enarbolar el pendón de la esperanza concreta. Por este motivo, Bloch es crítico del marxismo mecanicista que eclipsa la actividad humana. Totalmente alejada de esta postura, su heterodoxia filosófica reconoce el valor decisivo de la intervención humana en el tránsito del reino de la necesidad al de la libertad. Por ello, sostiene Bloch que el hombre mira al mundo como una tarea, como un intento para el que no existen ejemplos preestablecidos, $y$

(...) en tanto que en el hombre la capacidad activa forma parte muy especialmente de la posibilidad, la puesta en marcha de esta actividad y valentía, siempre que tiene lugar, causa un predominio de la esperanza ${ }^{7}$.

Hablamos de posibilidad subjetiva en correspondencia con la apertura del mundo, porque si el hombre viviese en la cárcel de las cosas clausuradas, no podría moverse ni respirar. Por lo tanto, sólo en un mundo indeterminado cabe el papel de un sujeto que, ejerciendo su libertad, estabilice las contradicciones o se apresure a solventarlas. Así lo establece Gimbernat: 
No existe ninguna bola de cristal en la que se reflejen los sucesos del porvenir. Tal interpretación haría un flaco favor a una filosofía que considera factor constitutivo a la praxis, con lo que ésta tiene de movilización subjetiva, de discusión estratégica y, en definitiva, de componente impredecible ${ }^{8}$.

Pues bien, como hemos explicado, la primacía subjetiva hunde sus raíces en la herencia marxiana, específicamente en la categoría de praxis. Sin embargo, existe un segundo fundamento de esta primacía que evidencia la originalidad de la antropología blochiana, a saber, la conciencia anticipadora. La función de esta modalidad de conciencia reside en atisbar el futuro y construir utopías concretas, luchando por cambiar las carencias del ahora en condiciones socio-políticas verdaderamente humanas. Bloch lo explica de la siguiente manera:

La dimensión profunda del factor subjetivo se halla precisamente en su reacción, porque esta no es sólo negativa, sino que, exactamente en el mismo sentido, contiene en sí la presión hacia un logro anticipado, y representa esta presión en la función utópica9 .

El hombre percibe que en el mundo existen tareas pendientes, situaciones que necesitan rectificarse u objetivos por concretar. Esos elementos que todavía no son -plano ontológico- se manifiestan en la subjetividad como lo aún no consciente, pues su clarificación resulta ascendente mediante el estudio pormenorizado de la realidad objetiva. Por lo tanto, sujeto y objeto se relacionan nuevamente, esta vez en la anticipación psíquica de lo posible real. Esto último representa la definición de función utópica, pues, según Bloch,

(...) el punto de contacto entre el sueño y la vida -sin el cual el sueño no es más que utopía abstracta y la vida sólo trivialidad- se halla en la capacidad utópica reintegrada a su verdadera dimensión, la cual se halla siempre vinculada a lo real-posible ${ }^{10}$. 
Como vemos, la praxis en Bloch encuentra una compañera de viaje, a saber, la conciencia anticipadora, que en su búsqueda inclaudicable erige utopías concretas. Por este motivo, su fuerza para avizorar un mañana mejor no se presenta como narcótico para soportar situaciones injustas, sino como bandera de lucha para su transformación. Y precisamente, en la procura de sus proyectos la acción humana tiene que precaverse del aislamiento, del fatal activismo golpista que se lanza sin más en procura de sus objetivos. Sólo bajo esta perspectiva emerge la esperanza, retoño militante de la conciencia anticipadora y la utopía concreta. Por eso, Gimbernat afirma que...

\title{
(...) la esperanza explica la importancia del factor subjetivo en el sistema de Bloch. La esperanza militante, activa (...) su misión es prefigurar el andar erguido del hombre, y es el que anticipa el rostro humano de la humanidad des- alienada ${ }^{11}$.
}

La conciencia anticipadora, prefigurando el andar humano por derroteros más justos, constituye el segundo fundamento de la primacía subjetiva en Bloch. Solamente el hombre posee la capacidad de prefigurar un mejor futuro en el aún no consciente, lugar donde la esperanza juega un rol prioritario y ascendentemente clarificador. Es en virtud de este deseo y la infatigable búsqueda de proyectos mediadores que Jiménez interpreta al sujeto blochiano como

\begin{abstract}
(...) algo que todavía es para sí mismo básica y esencialmente un misterio, todavía ni tan siquiera del todo presente y por eso mismo con historia. Con todo su mundo aún en marcha, con las instrucciones aún por descifrar, aunque posiblemente esclarecibles a lo largo del viaje de su propio descubrimiento, y sólo así sobre la marcha, realizables ${ }^{12}$.
\end{abstract}

En conclusión, la esperanza es una bandera política al servicio de la transformación del mundo. Y en este sentido, si la esperanza en Bloch, vinculada con un mundo abierto, dinamiza el advenimiento de proyectos políticos humanizadores, ¿qué elemento mediador imprime fuerza a su objetivo? Bloch establece a la razón como dinamizadora de la esperanza. En este sentido, resulta pertinente establecer la función que 
Bloch otorga a la razón, ya que ésta no efectúa una represión de los afectos que brotan en la anticipación; más bien les otorga mediaciones que les permitan convertirse en proyectos políticos. Por eso, dirá Bloch que...

(...) sólo cuando la razón comienza a hablar, comienza, de nuevo, a florecer la esperanza en la que no hay falsía. Y las representaciones de la fantasía no son tampoco representaciones compuestas simplemente a capricho por elementos dados -como mar de piedra y montaña de oro-, sino que son representaciones que prolongan anticipadamente lo dado en las posibilidades futuras de su ser-distinto, sermejor $^{13}$.

En la antropología blochiana el desciframiento de lo humano inmiscuye tanto a los afectos como a la razón; no para discutir cuál de los dos elementos posee mayor importancia en el actuar humano, sino para vincularlos en una praxis liberadora. La exclusividad de la razón o de los afectos es descartada por Bloch; cualquier reduccionismo sucumbe ante la mancuerna que éstos conforman, brindándole fuerza a la actividad humana. Por eso, la propuesta de Bloch sustenta una razón práctica, donde la pregunta: ¿qué debemos hacer?, ocupa un lugar central. La razón puede conocer el fin y el camino, sin embargo, necesita siempre de la conciencia anticipadora para realizar su praxis. Así expresa Vicente Ramos esta característica del filosofar blochiano:

El cambio verdadero exige, pues, conciencia anticipadora, que no es meramente fantasear, sino analizar las situaciones, descubrir las tendencias y posibilidades reales de las que el presente está grávido, pero, a su vez, reconocer y no perder de vista el humanum utópico. No hay racionalidad práctica sin conciencia anticipadora, sin intención utópica, que busca en el horizonte de la tendencia a acelerar y de las latencias que hay que hacer salir ${ }^{14}$.

El párrafo es sugerente: para Bloch la razón no puede florecer sin esperanza, es decir, desechando la función de la conciencia anticipadora que la sostiene: hurgar en los sueños para precipitar su concreción en el ahora. Por eso, el estudio pormenorizado de los afectos y sus mediaciones racionales, no implica en Bloch el sacrificio del presente 
por un futuro asintótico, es decir, arrojado al callejón de las promesas anquilosadas en el porvenir. Por el contrario, una constante experimentación de fragmentos utópicos caracteriza la existencia humana en el ingente laboratorio que representa el mundo. Por eso afirma Vicente ramos que en Bloch...

(...) la utopía labora sólo por razón del presente a alcanzar, y por eso el presente se encuentra al final, como la falta de distancia finalmente querida, salpicando todas las distancias utópicas. Precisamente porque la conciencia utópica no se deja alimentar con lo malo existente, precisamente porque es necesario el telescopio que se llama utopía concreta: por eso precisamente la utopía no pretende una distancia eterna del objeto, sino que desea, más bien, coincidir con él como un objeto que ya no es ajeno al sujeto ${ }^{15}$.

En este sentido, el telescopio de la utopía concreta implica dos momentos: primero, reconoce en cada suceso histórico o cultural el talante inconcluso de los proyectos llevados a la práctica, pues aún falta la concreción real de aquellos ideales que en el momento emancipatorio representaron fuentes de inspiración y beligerancia. Segundo, ante esta situación, la herencia cultural recupera estos ideales y enriquece utopías, que por mediación de la razón práctica, adquieren el grado de concreción imprescindible para que su lucha por una sociedad más justa sea efectiva.

El ahora se torna altamente activo; es allí donde se examinan los sueños pendientes de concreción y se estudian exhaustivamente las mediaciones que permitan convertirlos en realidad. Por ende, anticipación del futuro y recuperación del pasado, solamente acaecen en la praxis que lucha por transformar el ahora. Por ello, la razón práctica de Bloch posee un imperativo categórico de origen marxiano: "echar abajo todas las relaciones humanas en las cuales el hombre es un ser envilecido, humillado, abandonado y despreciado"16.

En resumen, la propuesta antropológica de Ernst Bloch vincula y complementa los afectos y la razón. La conciencia anticipadora encuentra su mediación en la razón práctica, que lucha por eliminar cualquier situación en la cual el hombre sea sojuzgado. La construcción de una sociedad donde la libertad y la justicia dejen de ser ideales sin concreción amalgama en la praxis los sueños humanamente sentidos y la razón.

Es importante subrayar en este punto que Bloch concibe la ca- 
pacidad de soñar como elemento constitutivo del hombre. ¿Quién puede cerrar la puerta a los sueños? ¿Quién no ha experimentado su capacidad de soñar? La humanidad lo hace desde que sus estructuras psicosomáticas lo permiten y sin embargo, la filosofía ha prestado poca atención a esta peculiar característica. Ante esta situación y haciendo gala de su heterodoxia, Bloch se pronuncia elaborando desde su marxismo cálido una reflexión sobre los sueños que, según nuestro autor, inicia a temprana edad:

Hacia los trece años se descubre el yo arrebatador, y es por ello que, hacia esta época, crece con especial exhuberancia los sueños de una vida mejor (...) Incluso la cabeza más mediocre se cuenta en esta edad historias, fábulas senciIlas, en las que le va bien. Forja las historias camino de la escuela o durante un paseo con amigos, y siempre, como un cuadro de encargo, el que relata se encuentra en medio del relato. Se intenta la felicidad, que sabe a prohibido y hace todo nuevo ${ }^{17}$.

El abordaje blochiano de los sueños analiza las diversas etapas de la vida humana. Cada fragmento escrito sobre este tema encierra experiencias que testifican la aventura de soñar; sobre todo cuando la juventud es objeto de estudio. No obstante, más allá de los relatos que encierran singulares sueños de cada edad, sobresale una exigencia de su sistema filosófico, a saber, dotar de un vehículo efectivo a la esperanza. El hombre, por su condición de ser insatisfecho, atisba en los sueños las posibilidades a realizar y también lo nuevos retos cuando sus proyectos no alcanzan concreción. Pues, como explica Bloch,

(...) también la esperanza desengañada vaga dolorosamente como un fantasma que ha perdido el camino de regreso al cementerio, y pende de representaciones desmentidas. No perece en ella misma, sino sólo en una nueva configuración de ella misma. Que se puede navegar así en sueños, muy a menudo sin garantía, esto es lo que caracteriza el gran lugar de la vida todavía abierta, todavía incierta en el hombre ${ }^{18}$. 
La inseguridad y frustración que el ser humano experimenta torna imposible la abdicación del soñar. Su apertura radical permite que los objetivos se renueven constantemente y el manantial de esta reingeniería se ubica para Bloch en los sueños. En este sentido, el sujeto que percibe conscientemente el impulso del hambre se encuentra pletórico de sueños; su transcurrir por el mundo representa una persuasiva indagación por mejorar las condiciones que encuentra. En este sentido, Javier Oroz describe con las siguientes palabras esta capacidad humana de vislumbrar el futuro a través del sueño:

\begin{abstract}
La conciencia, cautiva en su indigencia y acuciada por el hambre, suscita en los sueños imágenes de futuro. Es un recurso de la sabia naturaleza que prevé y hace prever lo más espléndido que guarda en las bodegas de la posibilidad. Si el universo en su totalidad es tensión, proyección, búsqueda vehemente de su madurez, la conciencia, parte privilegiada del universo, reflejará, cual poderoso espejo, la estructura real del universo al que pertenece ${ }^{19}$.
\end{abstract}

Ahora bien, esa capacidad de soñar no se circunscribe únicamente al ámbito nocturno, sino que brota sobre todo en la vigilia. Para Bloch, también con los ojos bien abiertos pueden acontecer en el interior cosas bastante abigarradas y prometedoras. Nuestro autor es conciente de la escasa atención prestada a los sueños diurnos, explicable en gran medida por la fas- cinación que ha representado para la humanidad descifrar los sueños nocturnos, olvidando que en el día la conciencia proyecta con mayor ahínco. Por esta razón, su intención no consistirá únicamente en mostrar la importancia del sueño de vigilia, sino otorgarle primacía con respecto a los acaecidos por la noche. Bloch acude nuevamente a la experiencia cotidiana y afirma que:

(...) los hombres no solo sueñan durante la noche ni mucho menos. También el día tiene bordes crepusculares, también en él se satisfacen los deseos. A diferencia del sueño nocturno, el sueño diurno dibuja en el aire figuras libremente escogidas y repetibles, puede entusiasmar y fabular, pero también meditar y proyectar ${ }^{20}$. 
La intención blochiana de rescatar los sueños diurnos no debe entenderse como un ataque aniquilador lanzado contra el sueño nocturno. Bloch admite las dos dimensiones del sueño y es más, reconoce que cuando la noche y el día se entrelazan los objetivos pueden alcanzar un mayor grado de significación para el ser humano. No obstante, es enfático en afirmar que sólo en los sueños desiderativos diurnos los contenidos de la noche pueden ser rectificados. Y esto por un motivo capital: es aquí donde el hombre permanece plenamente despierto y activo. Recordemos que la esperanza labora en el campo de lo consciente, donde se estudian y planean los modos de concretar sus objetivos. Por lo tanto, la primera característica de los sueños diurnos, que permite a Bloch aseverar su primacía es el ego mantenido. Solamente ante una conciencia despierta la energía y expe- riencia puede albergar la posibilidad que un sueño diurno se convierta en realidad, mientras que Morfeo no tiene más brazos que aquellos sobre los que reposa.

En este sentido, podemos establecer una diferencia que nos ayude a explicar mejor la primacía de los sueños diurnos defendida por Bloch. En efecto, el ego mantenido puede interpretarse desde el contraste existente entre los impulsos de deseo y querer, tomando en cuenta su aparición en cada modalidad de sueño. En efecto, por las noches el sujeto puede desear, lo cual implica la existencia de situaciones totalmente inalcanzables $y$, a veces, incomprensibles. Un escenario distinto se genera en el sueño diurno, donde los sentidos están atentos y el querer apunta siempre hacia objetivos realizables. Tomando en cuenta estas divergencias afirma Bloch que

El sueño desiderativo diurno no necesita ni excavación ni interpretación, sino rectificación y también, cuando es susceptible de ello, concreción. En resumen, lo mismo que el sueño nocturno, tampoco el diurno tiene de por sí un criterio; pero, a diferencia de las fantasmagorías nocturnas, sí tiene un objetivo y se mueve en su dirección hacia adelante ${ }^{21}$.

Para Bloch la noche sólo puede decir algo si está iluminada por la fantasía diurna, pues esta se dirige siempre a mejorar el mundo, lo cual constituye la segunda característica de los sueños diurnos. Y es comprensible, pues ante un sistema filosófico abierto y donde la esperanza tiene la última palabra, los sueños de vigilia deben procurar una transformación de la realidad; por eso deben pasar la criba de la docta spes para ser verdaderas banderas de cambio. Pues el que duerme se encuentra a solas con sus deseos, mientras el sujeto que desea imple- 
mentar proyectos políticos necesita aglutinar esfuerzos para que sus fantasías diurnas movilicen voluntades.

La perspectiva política en Bloch surge nuevamente, esta vez inundando los sueños de vigilia. No existe categoría antropológica que no persiga esta intención. Es im- posible desligar el vehículo de la esperanza de la utopía concreta, pues el objetivo por mejorar el mundo tiene como horizonte posible el Totum, que consiste en procurar la reconciliación del ser humano con la naturaleza. Por eso afirmará Bloch que las

\section{(...) anticipaciones e intensificaciones referidas a personas, utópico-sociales y vinculadas a la belleza, sólo se dan en el sueño diurno. El interés revolucionario, que sabe cuán defectuoso es el mundo y que conoce cuánto mejor podría ser, precisa del sueño despierto del perfeccionamiento del mundo; más aún, se aferra a él en la teoría y en la práctica, y no sólo de modo instrumental, sino de manera absoluta- mente objetiva ${ }^{22}$}

Una antropología política es el legado de Bloch y contiene un corolario: es imposible examinar al ser humano abstraído de sus condi-

NOTAS

$1 \quad$ Nogueira Dobarro, A., "El principio esperanza, estructura fundamental del ser humano”, en Revista Anthropos (146-147) 1993, p. 7.

2 Bloch, E., El principio esperanza, tomo I, Aguilar, Madrid, 1984. p. 284.

$3 \quad$ Ibid., p. 240.

$4 \quad$ Bloch, E., "El hombre como posibilidad", en Revista Anthropos (41), p. 25.

5 Bloch, E., El principio esperanza, Op.Cit. p. 254.

$6 \quad$ Ibid., p. 25. ciones materiales y objetivas, pero resulta también inviable estipular el desarrollo de éstas sin la esperanza como principio.

7 Bloch, E., El principio esperanza, Op.Cit. p. 240.

8 Gimbernat, J., Ernst Bloch, utopia y esperanza, Op.Cit. p. 45.

$9 \quad$ Bloch, E., El principio esperanza Op.Cit. p.138. Cursivas en el original.

$10 \quad$ Ibid., p. 135.

11 Gimbernat, J., Ernst Bloch, utopia y esperanza, Op.Cit. p. 71.

12 Vasco Jiménez, M., "La ontología en Bloch,” en Revista Anthropos (146147), p.10.

13 Bloch, E., El principio esperanza Op.Cit. p. 134. 
14 Ramos, V., "Racionalidad práctica y utopía”, en revista Anthropos (146147), p. 72.

$15 \quad$ Ibid., p. 312.

16 Marx, K. Introducción para la critica de la filosofía del derecho de Hegel, Editorial Claridad, Buenos Aires, 1955. p. 15.

17 Bloch, E., El principio esperanza, tomo I, Op.Cit. p. 6.
$18 \quad$ Ibid., p. 178.

19 Oroz Ezcurra, J., La última esperan$z a$, en torno al filósofo Ernst Bloch $y$ otras reflexiones, Universidad de Deusto, Bilbao, 1989. p. 129.

Bloch, E., El principio esperanza, tomo I, Op.Cit. p. 73.

$21 \quad$ Ibid., p. 87.

22 Ibid., p. 83. 